\title{
Effect of humic preparation and herbicide treatment on chernozem aggregate composition
}

\author{
Vladimir Lychman ${ }^{1,}$, Olga Bezuglova ${ }^{1}$, Marina Dubinina ${ }^{1}$, Olga Naimi $^{1}$, and Elena \\ Polienko $^{1}$ \\ ${ }^{1}$ Federal State agrarian research center of Rostov, 1 Institutskaya street, 346735, village Rassvet, \\ Aksay district, Rostov region, Russia
}

\begin{abstract}
The influence of the humic preparation and pesticides on dynamics of soil carbohydrates and the soil structure of ordinary chernozem during the cultivation of winter wheat and chickpeas was studied. A positive trend in the growth of the structural coefficient was observed in all variants. This dynamic was confirmed statistically when a humic preparation and pesticides were used together: the difference with the control after treatment was $1.54 \%$ (2019). A decrease in the number of water-resistant units from 87.4 to $56.6 \%$ was observed on the control during the entire field experiment. There was a statistically significant increase of water-resistant aggregates by $1.9-5.4 \%$ when pesticides are applied together with a humic preparation. The growth of the aggregate water resistance criterion (API) from $6.0 \%$ to $17.2 \%$ was observed in the variant with a humic preparation. The dynamics of soil carbohydrates in all variants in 2017-2018 was insignificantly expressed. The sharp increase in the content of carbohydrates in 2019 is probably associated with a change of culture in the crop rotation link from winter wheat to chickpea. The amount of carbohydrate compounds varies from 1.13 in the control to $1.26 \%$ in the variant with the combined use of pesticides and a humic preparation.
\end{abstract}

\section{Introduction}

Intensive agriculture requires a high level of agrochemical resources use, including fertilizers and pesticides. The significant scale of the removal nutrients from the soil with the crop can be compensated by additional application of both mineral and organic fertilizers. At the same time, it is very difficult to qualitatively improve the agrophysical properties of soils using mechanical processing. According to numerous studies, frequent mechanical treatment causes the formation of a "plow sole" - an over-compacted soil layer, which, in turn, disrupts the water-air regime. At the same time, there are data showing that the minimum tillage systems do not create a sufficient supply of moisture, and due to the active use of pesticides completely exclude the effect of the so-called "biological loosening" [1,2]. According to Guohua Rong [3], in soils subject to intensive agriculture, the organic matter decomposition is carried out by creating a new pool of microorganisms

\footnotetext{
*Corresponding author: 1ykvladimir@yandex.ru
} 
and enzymes, therefore, the maximum formation of water-resistant aggregates in these soils occurs in several months after treatments. In this case, the most effective method is a combination of traditional agrochemical plant protection products, mechanical soil cultivation and the use of humic preparations that perform a stress-protective function.

It has been found that substances belonging to the class of carbohydrates, due to their adhesive properties, directly and indirectly affect the formation of a macroaggregate structure [4]. This issue was studied by Kumar V [5], however, to date, no detailed information has been obtained on the effect of artificial introduction of polysaccharides on the structural and aggregate composition of the soil. The results of scientific research indicate a direct correlation between the carbohydrate content and the amount of agronomically valuable soil aggregates [6,7]. It is also noted that the destruction of cementing organic substances by means of chemical reagents has a negative effect on the water resistance of soil units [8].

Some scientific works mention the coagulating property of microbial secretions due to the presence of substances from the class of polysaccharides $[9,10]$. It should be noted that the structure-forming ability of compounds of a microbiological nature is more pronounced than substances produced by plants [11]. Legumes are an exception, since their roots contain nodule bacteria, which causes the release of more pectin substances than the roots of cereal plants. Therefore, the formation and development of the root system of legumes has a significant effect on the soil agrophysical qualities and its aggregate composition [12]. In water-stable soil aggregates with a low content of total carbon (up to $1 \%$ ), polysaccharides are found predominantly; therefore, they are primarily involved in structure formation [13].

The structure-forming role of carbohydrates has also been shown for the chernozems of the Rostov region. According to research, the cementing properties of polysaccharides are associated with factors of various nature, for example, the linear structure of molecules such a spatial orientation of molecules, which creates conditions for the manifestation of Van-der-Waals forces; a large number of $\mathrm{OH}$ groups that are capable to form hydrogen bonds; the presence of acidic groups $-\mathrm{COOH}$, which can carry out ionic interactions through 2- and 3-valence cations [14].

The aim of the study was to determine whether the multidirectional effect of the introduced substances (herbicides and humates) affects the content of soil polysaccharides and their binding capacity, and, as a consequence, to find out what is the specific feature of the individual and combined effects of the use of herbicides and humic preparations on the formation of the soil structure and its water resistance.

\section{Materials and research methods}

The place of field experiments was the Aksay district of the Rostov region. This region belongs to the Azov agricultural zone, which is characterized by an arid, moderately hot, continental climate. The relative humidity of the air has a pronounced annual variation. Its lowest values are observed in July $-50 \ldots 60 \%$, the minimum on some days can be $25 \ldots$ $30 \%$ and lower, which already indicates drought. The photosynthetically active radiation during the growing season is $3.5 \ldots 4.0$ billion $\mathrm{kcal} / \mathrm{ha}$.

Soil - ordinary calcareous chernozem (north-Azov), according to the soil classification of Russia (2004) - migration-segregation chernozem. A distinctive soil characteristic: the thickness of the humus horizon is $75 \ldots 100 \mathrm{~cm}$, with a low humus content $-3.9 \ldots 4.7 \%$, a peculiar nutty-lumpy structure, characterized by looseness and friability, a high level of carbonate content (effervescence from $10 \% \mathrm{HCl}$ in horizon $\mathrm{A}$ ), presence of coprolites and worm passages, poorly cemented character of carbonate formations (white-eyed). Ordinary carbonate chernozem is well structured. Its mechanical elements are coagulated into strong 
aggregates, the predominant part of which (more than 60\%) in terms of size refers to agronomically valuable fractions $-10 \ldots 0.25 \mathrm{~mm}$. The density of the soil in the humus horizon does not exceed 1.4, in the arable layer it ranges from 1.0 to $1.2 \mathrm{~g} / \mathrm{cm}^{3}$. The arable layer has quite satisfactory porosity - $50 \ldots 66 \%$ of the soil volume, providing high air capacity and gas exchange [15].

The soil of the studied field has been cultivated for about 50 years, therefore, the effect of soil fatigue may gradually appear, which is expressed in the accumulation of pathogens and pests, a decrease in yield and, as a consequence, a deterioration in agrophysical properties. To eliminate these consequences, it is necessary to follow crop rotation and use pesticides to protect plants from various pests and diseases [16]. The agrophysical state of the soil is one of the indicators of soil fertility, which, although indirectly, reliably reflects the intensity of the soil biota development.

On the one hand, plant protection products make it possible to optimize the course of the growing processes of agricultural crops, suppressing the development of pathogenic microflora and blocking the weeds growth. On the other hand, when crops are treated with chemicals, due to the nonspecificity of their effect, soil microbiological activity can be inhibited, and in this case, a humic preparation acts as a stress-protective factor [17].

The combination of these factors led to the choice of the study design (Table 1). The crops cultivated in this link of the crop rotation are winter wheat and chickpeas. According to the experiment scheme, the crops of winter wheat are treated with a tank mixture of a pesticide and a humic preparation in the tillering phase (study period 2017-2018), and chickpea crops are treated in the phase of beans formation (study period 2019). All variant, including control, were fertilizedwith $\mathrm{NH}_{4} \mathrm{NO}_{3}$ at a dose of $100 \mathrm{~kg} / \mathrm{ha}$.

Table 1. The experiment scheme.

\begin{tabular}{|c|c|c|c|}
\hline \multirow[b]{2}{*}{ Variant } & \multicolumn{2}{|c|}{ Herbicide / dosage } & \multirow{2}{*}{$\begin{array}{l}\text { Humic } \\
\text { preparation } \\
\text { BIO-Don }\end{array}$} \\
\hline & $2017-2018$ & 2019 & \\
\hline 1 - Control & - & - & - \\
\hline 2 - Herbicides treatment & $\begin{array}{l}\text { GranstarPro / } \\
15 \mathrm{~g} / \mathrm{ha}\end{array}$ & $\begin{array}{l}\text { Gezagard KS / } 3 \\
1 / \text { ha }\end{array}$ & - \\
\hline 3 - BIO-Don treatment & - & - & $21 /$ ha \\
\hline $\begin{array}{l}4 \text { - BIO-Don }+ \text { herbicide } \\
\text { combined treatment }\end{array}$ & $\begin{array}{l}\text { GranstarPro / } \\
15 \mathrm{~g} / \mathrm{ha}\end{array}$ & $\begin{array}{l}\text { Gezagard KS / } 3 \\
1 / \text { ha }\end{array}$ & $21 /$ ha \\
\hline
\end{tabular}

The herbicide Granstar Pro from the sulfonylurea class was used to treat winter wheat from dicotyledonous weeds. The herbicide Gezagard KS from the class of triazines was used to treat chickpea from annual dicotyledonous and cereal weeds. The humic preparation BIODon is a vermicomposting product of vermicompost, contains $2 \ldots 2.5 \mathrm{~g} / 1$ of humic acids.

The selection of soil samples was carried out from the arable layer at the following times: before sowing and before processing with a tank mixture, and 2 weeks after processing: in the tillering phase on winter wheat; in the phase of beans formation - on chickpeas. For the cultivation of the studied crops, the agricultural technologies recommended for the Azov zone of the Rostov region were used. Sampling of soil was carried out according to GOST 28186-89. Determination of the structural state of the soil according to GOST method 12536-79. The "dry" and "wet" sieving was used according to the method of N.I. Savvinov to determine the soil structure. We also calculated the structure coefficients and water resistance of soil aggregates. Determination of carbohydrates was carried out by the phenol sulfuric acid method of Dubois in fractions of $5 \ldots 3 \mathrm{~mm}, 3 \ldots 2$ $\mathrm{mm}, 2 \ldots 1 \mathrm{~mm}$, as prevailing in the studied chernozems, and due to the rather high water resistance of aggregates of this dimension [18]. The diagrams were constructed using MS Excel. 


\section{Results and discussion}

Table 2 shows the data of calculating the coefficient of structure in the studied ordinary carbonate chernozem. As can be seen from the results, in the control variant, the structural coefficient increases from 1.36 to 5.44 during 2017-2018.In 2019this indicator decreases to 2.58 , thenit increases to 4.48 . Such dynamics in the control variant is explained by a number of reasons.In particular, mechanical soil cultivation with agricultural tools and the introduction of mineral fertilizers, which, of course, have a positive effect on the vegetation processes of agricultural crops, since they directly affect the supply of plant nutrients [19].

Table 2. Dynamics of the structure coefficient in ordinary carbonate chernozem according to the variants of the experiment in $2017-2019$.

\begin{tabular}{|c|c|c|c|c|}
\hline Variant & Before treatment & $\begin{array}{l}\text { Comparison with } \\
\text { background }\end{array}$ & $\begin{array}{l}\text { After treatment } \\
\text { with herbicides }\end{array}$ & $\begin{array}{l}\text { Comparison } \\
\text { with } \\
\text { background }\end{array}$ \\
\hline \multicolumn{5}{|c|}{2017} \\
\hline 1 & 1.36 & - & 3.92 & - \\
\hline 2 & 2.55 & +1.19 & 4.20 & +0.28 \\
\hline 3 & 2.78 & +1.42 & 2.81 & -1.11 \\
\hline 4 & 2.66 & +1.30 & 5.26 & +1.34 \\
\hline $\mathrm{LSD}_{0,05}$ & - & 1.43 & - & 1.30 \\
\hline \multicolumn{5}{|c|}{2018} \\
\hline 1 & 4.72 & - & 5.44 & - \\
\hline 2 & 4.89 & +0.17 & 5.30 & -0.14 \\
\hline 3 & 6.04 & +1.32 & 5.36 & -0.08 \\
\hline 4 & 4.87 & +0.15 & 5.94 & +0.50 \\
\hline $\mathrm{LSD}_{0,05}$ & - & 1.31 & - & 1.16 \\
\hline \multicolumn{5}{|c|}{2019} \\
\hline 1 & 2.58 & - & 4.48 & - \\
\hline 2 & 3.93 & +1.35 & 4.82 & +0.34 \\
\hline 3 & 3.76 & +1.18 & 5.29 & +0.81 \\
\hline 4 & 3.55 & +0.97 & 6.02 & +1.54 \\
\hline $\mathrm{LSD}_{0,05}$ & - & 1.41 & - & 1.08 \\
\hline
\end{tabular}

*LSD - the least significant difference

On the variant with chemical plant protection products, the structural coefficient varies from 2.55 at the beginning of the field experiment to 5.3 in 2018.In general, there is a positive trend if compared with the control: the difference in the structural coefficients of the variants increases from 0.17 to 1.35 . A similar situation develops in the variant with a humic preparation, however, in both cases, the differences with the control do not exceed a statistically significant value, which allows us to speak of an unexpressed effect of chemical protection agents and humic preparations at separate treatment ofcrops.

The indicator of the ratio of agronomically valuable aggregates to agronomically invaluable ones after treatment with a tank mixture of herbicides and a humic preparation ranges from 3.55 to 6.02 . The difference for this indicator in comparison with the control variant is from 0.97 to 1.54 , and these values are statistically significantin 2017 and 2019 . This result allows us to note the positive effect of the combined use of chemical protection agents and a humic preparation in tank mixtures, since no reliable positive dynamics is observed in the other three variants.

Indicators of the optimal water-air regime in the soil are not only the quantitative content of agronomically valuable aggregates, but also their qualitative characteristics, in particular, their ability to resist the erosion effect of water - water resistance. Figure 1 shows the results of determining the number of such aggregates by the wet sieving method. 


\section{Dynamics of the content of water-resistant aggregates}

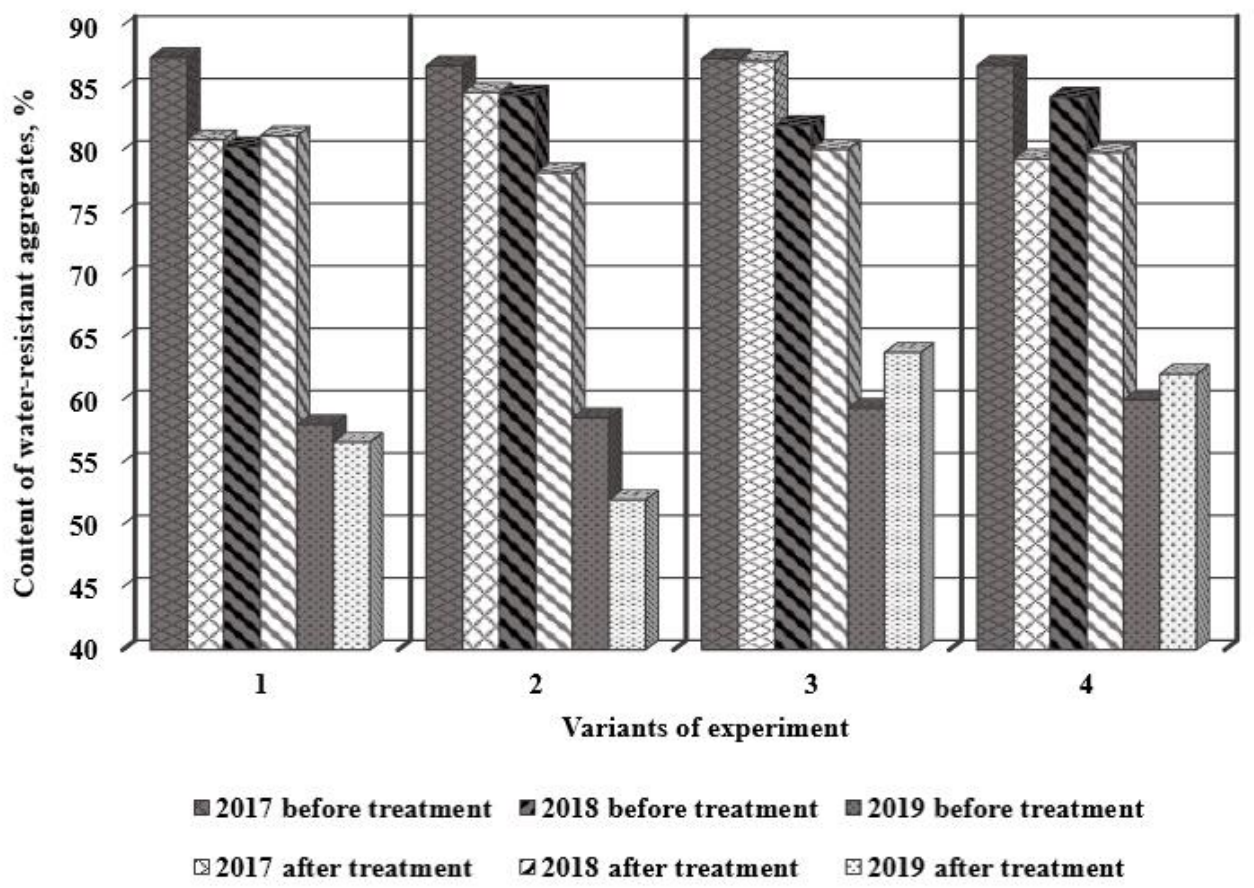

Fig. 1. Dynamics of the content of water-resistant aggregates in ordinary carbonate chernozem according to the variants of the experiment in 2017-2019.

As seen from Figure 1, there is a decrease in the number of water-resistant units during the entire field experiment on the control variant from 87.4 to $56.6 \%$, which, according to S.I. Dolgov and P.U. Bakhtin corresponds to a change from an excellent state to a satisfactory one. This situation is typical for all variants of the experiment, which is probably explained by general factors associated primarily with the dispersing properties of mineral fertilizers to soil colloids, as well as the consequences of soil fatigue, which are expressed in a decrease of the soil organic matter, which the water resistance of soil aggregates depends on.

The question of the influence of the amount of free organic colloids in the soil on the soil agronomic structure was raised in the works of Adnan Mustafa [20]. The dependence turned out to be quite definite: the removal of free humates from chernozems was accompanied by the disintegration of macroaggregates, although all colloids were then saturated with calcium cations.

There is generally positive dynamics of water resistanceif we compare the variants of our experiment with the control. In the variant with chemical plant protection agents, the changes were recorded as a trend: the increase was from 0.6 to $3.8 \%$. In the variant with the introduction of a humic preparation in 2017, the content of water-resistant aggregates increases after treatment by $6.3 \%$ with the least significant difference of $4.2 \%$. In 2019 , after treatment, the positive difference with the control is already $7.2 \%$, with the least significant difference being $5.2 \%$. When using chemical plant protection products in conjunction with a humic preparation, the situation is similar: the increase of water-resistant aggregates is from 2.0 to $5.4 \%$, which is statistically significant. 
An additional indicator of the quality of an agronomically valuable structure is the Agrophysical Institute criterion (API criterion), calculated as the ratio of the sum of fractions $1 \ldots 0.25 \mathrm{~mm}$ in size according to the results of "wet" and "dry" sieving in \% (Table 3).

Table 3. Dynamics of the API criterion in ordinary carbonate chernozem by variants of the experiment in $2017-2019$.

\begin{tabular}{|c|c|c|c|c|}
\hline \multirow[b]{2}{*}{ Variant } & \multicolumn{4}{|c|}{ API criterion, $\%$} \\
\hline & Before treatment & $\begin{array}{l}\text { Comparison with } \\
\text { control }\end{array}$ & Aftertreatment & $\begin{array}{l}\text { Comparison } \\
\text { with control }\end{array}$ \\
\hline \multicolumn{5}{|c|}{2017} \\
\hline 1 & 161.9 & - & 122.6 & - \\
\hline 2 & 149.1 & -12.8 & 114.3 & -8.3 \\
\hline 3 & 139.2 & -22.7 & 139.8 & +17.2 \\
\hline 4 & 164.6 & +2.7 & 135.8 & +13.2 \\
\hline $\mathrm{LSD}_{0,05}$ & - & 24.3 & - & 7.9 \\
\hline \multicolumn{5}{|c|}{2018} \\
\hline 1 & 352.7 & - & 179.3 & - \\
\hline 2 & 303.3 & -49.4 & 149.9 & -29.4 \\
\hline 3 & 332.7 & -20.0 & 176.2 & -3.10 \\
\hline 4 & 340.6 & -12.1 & 190.3 & +11.0 \\
\hline $\mathrm{LSD}_{0,05}$ & - & 52.1 & - & 9.3 \\
\hline \multicolumn{5}{|c|}{2019} \\
\hline 1 & 131.0 & - & 89.0 & - \\
\hline 2 & 115.0 & -16.0 & 86.0 & -3.0 \\
\hline 3 & 136.0 & +5.0 & 92.0 & +3.0 \\
\hline 4 & 141.0 & +10.0 & 95.0 & +6.0 \\
\hline $\mathrm{LSD}_{0,05}$ & - & 7.1 & - & 4.2 \\
\hline
\end{tabular}

*LSD - the least significant difference

According to the data presented in Table 3, at the laying of field experiment in 2017, the differences between the variants before treatment were not significant, which characterizes similar agrophysical soil properties in all four variants and indicates the homogeneity of the soil conditions of the experimental field. During the field experiment (2017-2019), there is a significant difference in the variants with a humic preparation, both separately introduced and used in conjunction with chemical means of protection. The increase in the API criterion varies from 6.0 to $17.2 \%$ with the smallest significant difference being 4.2 and $7.9 \%$, respectively.

For a detailed study of agrophysical properties, the following characteristics were studied: the biodynamics of soil carbohydrates, the content and characteristics of the polysaccharide complex of the soil, and especially the quantitative content of carbohydrates as the most labile fraction of humus in soils subject to erosion and technogenic change. According to the data obtained, there is a positive dynamic of the carbohydrates content in the fraction $5 \ldots 3 \mathrm{~mm}$ for all variants of the experiment (Figure 2). 


\section{Dynamics of the content of carbohydrates in soil aggregates of fraction $5 \ldots 3 \mathrm{~mm}$}

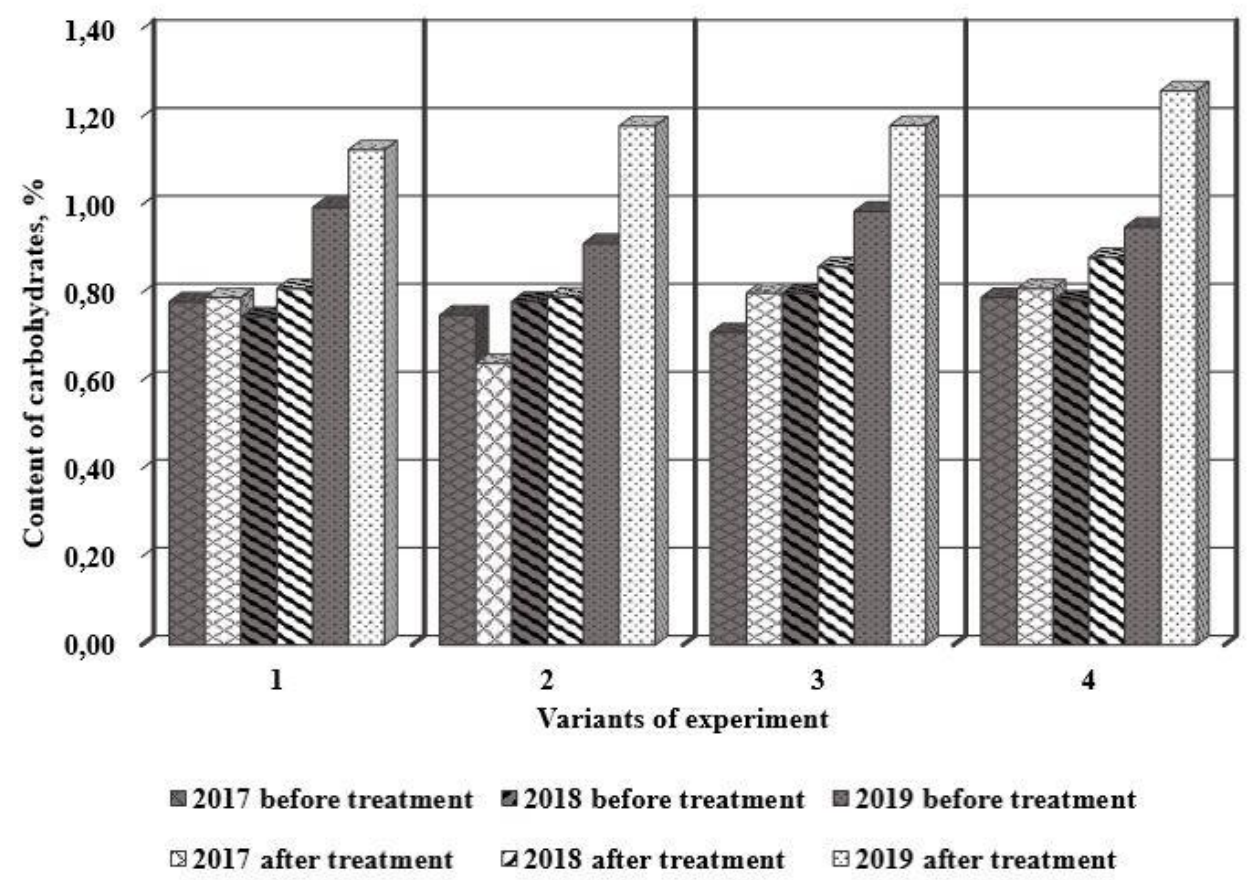

Fig. 2. Dynamics of the content of carbohydrates in soil aggregates of fraction $5 \ldots 3 \mathrm{~mm}$ of ordinary carbonate chernozem according to the variants of the experiment in 2017-2019

However, when comparing variants with control, the following trends are observed. The differences between the options in comparison with the control before treatment with preparations in 2017 are insignificant, the values vary from $-0.07 \%$ to $0.01 \%$ with the least significant difference by $0.09 \%$. After the introduction of the preparations, the carbohydrate content varies in the range from 0.64 to $0.81 \%$, while in the variant without the humic preparation, a decrease to $-0.15 \%$ is observed with the least significant difference by $0.11 \%$. These changes are similar to the API criterion trends presented in Table 3, where a statistically significant decrease is observed in the variant with chemical means of protection (X) in 2017 after treatment.

A decrease in the content of carbohydrates in the soil fraction of $5 \ldots 3 \mathrm{~mm}$ is also observed after the treatment of crops with a tank mixture in 2018 as a tendency, however, a statistically significant increase is found in the variants with a humic preparation and the joint application of chemical protection agents.

It should be noted a sharp increase in the content of carbohydrates in soil aggregates in 2019 , due to the change of culture in the link of the crop rotation from winter wheat to chickpea. The amount of carbohydrate compounds varies from 1.13 in the control to $1.26 \%$ in the variant with the combined use of chemical protection agents and a humic preparation, an increase in this indicator by $0.13 \%$ is statistically significant with $\mathrm{LSD}_{0.05}=0.11 \%$, which can be evidence of the manifestation of the stress-protective function of humic preparations.

In soil fractions of $3 \ldots 2 \mathrm{~mm}$ and $2 \ldots 1 \mathrm{~mm}$, the data on the dynamics of the content of carbohydrates are similar to those presented in Figure 2. 


\section{Conclusions}

The data obtained during the study prove that the maximum formation of water-resistant aggregates and the content of carbohydrates in them depends on the introduction of humic preparations indirectly, through biological processes occurring in the root layer of the soil. Chemical means of plant protection, due to their high toxic effect in relation to soil biota, indirectly worsen a number of agrophysical properties of soils, as indicated by a decrease in the coefficient of structure, the content of water-resistant aggregates and carbohydrates in soil fractions of $5 \ldots 3 \mathrm{~mm}$ in variants of chemical means of protectionuse. The combined application of pesticides and a humic preparation in a tank mixture is the most effective way from the point of view of environmental safety and rational use of chemical agents in crop production.

\section{References}

1. J. C. Sanchez-Hernandez, M. Sandoval, Ecotoxicology and Environmental Safety, 142, 303-311 (2017) https://doi.org/10.1016/j.ecoenv.2017.04.032

2. Z. Yu, J. Zhang, C. Zhang, et al., Soil and Tillage Research, 174, 251-260 (2017) https://doi.org/10.1016/j.still.2017.08.004

3. E. S. Vogelmann, J. M. Reichert, J. Prevedello, et al., Geoderma, 305, 374-381 (2017) https://doi.org/10.1016/j.geoderma.2017.06.024

4. S. Wei, X. Zhang, N. B. McLaughlin, et al., Jia, Aizhen Liang, Geoderma, 294, 63-69 (2017) https://doi.org/10.1016/j.geoderma.2017.01.021

5. Y. Wang, Y.-J. Cui, A. M. Tang, et al., Engineering Geology, 228, 167-172 (2017) https://doi.org/10.1016/j.enggeo.2017.08.005

6. A. B. Volikov, V. A. Kholodov, N. A. Kulikova, et al., Catena, 137, 229-236 (2016) https://doi.org/10.1016/j.catena.2015.09.022

7. S. Li, X. Gu, J. Zhuang, et al., Soil and Tillage Research, 155, 199-206 (2016), https://doi.org/10.1016/j.still.2015.08.009

8. P. Jouquet, S. Chintakunta, N. Bottinelli, et al., Applied Soil Ecology, 101, 117-123 (2016) https://doi.org/10.1016/j.apsoil.2016.02.001

9. V. Wendling, C. Legout, N. Gratiot, et al., Catena, 141, 66-72 (2016), https://doi.org/10.1016/j.catena.2016.02.015

10. T. Yin, C. Zhao, C. Yan, et al., Journal of Integrative Agriculture, 17 (11), 2546-2557 (2018), https://doi.org/10.1016/S2095-3119(18)61925-2

11. T. Mitran, P. K. Mani, P. K. Bandyopadhyay, et al., Pedosphere, 28 (5), 823-832 (2018), https://doi.org/10.1016/S1002-0160(17)60423-5

12. J.R. Sarker, B.P. Singh, A.L. Cowie, et al., Soil and Tillage Research, 178, 209-223 (2018), https://doi.org/10.1016/j.still.2017.12.019

13. V.A. Lyhman, O.S. Bezuglova, E.A. Polienko, et al., Nauchnyj zhurnal Rossijskogo NII problem melioracii, 1(37), 154-168 (2020), DOI: 10.31774/2222-1816-2020-1154-168

14. M. Arai, T. Miura, H. Tsuzura, et al., Geoderma, 332, 135-141 (2018), https://doi.org/10.1016/j.geoderma.2017.10.021

15. T. Li, Y. Zhang, S. Bei, X. Li, et al., Catena, 194 (2020), 104739, https://doi.org/10.1016/j.catena.2020.104739 
16. S. Liu, Z.C. Guo, Y.B. Pan, et al., Geoderma, 351, 36-48 (2019) https://doi.org/10.1016/j.geoderma.2019.05.015

17. R. Bu, T. Ren, M. Lei, et al., Agriculture, Ecosystems \& Environment, 287, 106681 (2020) https://doi.org/10.1016/j.agee.2019.106681

18. R. Huang, D. Tian, J. Liu, et al., Agriculture, Ecosystems \& Environment, 265, 576586 (2018) https://doi.org/10.1016/j.agee.2018.07.013

19. Y. Yan, X. Wang, Z. Guo, et al., Catena, 170, 159-168 (2018), https://doi.org/10.1016/j.catena.2018.06.013

20. Y. F. Guanglu Li, T.i Zheng, Y. Zhao, et al., Catena, 185, 104342 (2020) https://doi.org/10.1016/j.catena.2019.104342 